NBER WORKING PAPER SERIES

\title{
THE INFORMATION IN LONG-MATURITY FORWARD RATES: IMPLICATIONS FOR EXCHANGE RATES AND THE FORWARD PREMIUM ANOMALY
}

\author{
Jacob Boudoukh \\ Matthew Richardson \\ Robert Whitelaw \\ Working Paper 11840 \\ http://www.nber.org/papers/w11840 \\ NATIONAL BUREAU OF ECONOMIC RESEARCH \\ 1050 Massachusetts Avenue \\ Cambridge, MA 02138 \\ December 2005
}

aArison School of Business, IDC and NBER; bStern School of Business, NYU and NBER. We thank Philippe Jorion for providing us with term structure data. We are grateful to Thomas Philippon, Dave Backus and seminar participants at NYU, NYU Salomon Center, Research Conference for Corporate Associates, Tel Aviv University, and IDC for many helpful comments. Contact: Prof. R. Whitelaw, NYU, Stern School of Business, 44 W. 4th St., Suite 9-190, New York, NY 10012; rwhitela@ stern.nyu.edu. The views expressed herein are those of the author(s) and do not necessarily reflect the views of the National Bureau of Economic Research.

C2005 by Jacob Boudoukh, Matthew Richardson, and Robert Whitelaw. All rights reserved. Short sections of text, not to exceed two paragraphs, may be quoted without explicit permission provided that full credit, including () notice, is given to the source. 
The Information in Long-Maturity Forward Rates: Implications for Exchange Rates and the Forward Premium Anomaly

Jacob Boudoukh, Matthew Richardson, and Robert Whitelaw

NBER Working Paper No. 11840

December 2005

JEL No. G15, F31

\section{ABSTRACT}

The forward premium anomaly is one of the most robust puzzles in financial economics. We recast the underlying parity relation in terms of cross-country differences between forward interest rates rather than spot interest rates with dramatic results. These forward interest rate differentials have statistically and economically significant forecast power for annual exchange rate movements, both in- and out-of-sample, and the signs and magnitudes of the corresponding coefficients are consistent with economic theory. Forward interest rates also forecast future spot interest rates and future inflation. Thus, we attribute much of the forward premium anomaly to the anomalous behavior of short-term interest rates, not to a breakdown of the link between fundamentals and exchange rates.

Jacob Boudoukh

Arison School of Business, IDC

Kanfei Nesharim St.

Herzlia 46150

ISRAEL

and NBER

jboudouk@idc.il

Matthew Richardson

NYU, Stern School of Business

44 W. 4th St.

New York, NY 10012

and NBER

mrichar0@stern.nyu.edu
NYU, Stern School of Business

44 W. 4th St.

New York, NY 10012

and NBER

rwhitela@stern.nyu.edu

Robert Whitelaw 


\section{Introduction}

Well over a hundred papers document, in some form or another, the forward premium anomaly-namely, that future exchange rate changes do not move one-for-one with interest rate differentials across countries. In fact, they tend to move in the opposite direction (e.g., see Hodrick (1987) and Engel (1996) for survey evidence). In our data, we also obtain the standard anomalous regression coefficient. When regressing annual exchange rate changes on the beginning-of-year one-year interest rate differentials, the regression coefficient is indeed negative, e.g., -0.98 for the USD/DEM exchange rate. This anomaly has led to a plethora of papers over the last decade that develop possible explanations only to shoot them down. It is reasonable to conclude that the forward premium anomaly is one of the more robust puzzles in financial economics.

Parallel to work on the forward premium puzzle, another literature has developed, starting with Meese and Rogoff (1983), that documents an even more startling puzzle: exchange rates do not seem to be related to fundamentals. ${ }^{1}$ The random walk model has proven almost unbeatable, even against models with a variety of finance and macro variables.

This paper looks at the forward premium anomaly, and the fundamental determinants of exchange rates, in a novel way by recasting the parity relation in terms of future exchange rate movements against forward interest rate differentials across countries. In contrast to existing evidence, we find much more support for the theory. The one-year forward interest rate differential from year 1 to year 2 has a regression coefficient of 0.57 with the annual change in the USD/DEM exchange rate one year hence; the one-year forward interest rate differential from year 2 to year 3 has a regression coefficient of 0.86 with the annual change in the exchange rate in two years; and so forth.

This paper thus complements Fama and Bliss (1987) and Jorion and Mishkin (1991), who respectively show that long-maturity forward rates forecast future interest rates in the U.S. and internationally. Those papers reveal a dichotomous effect for short-maturity and long-maturity forwards, not unlike the forward premium result. This parallel is not by

\footnotetext{
${ }^{1}$ These findings are revisited and confirmed by Cheung, Chinn, and Garcia Pascual (2003) using updated data.
} 
chance, and relates directly to the commingling of the expectations hypothesis of the term structure and uncovered interest rate parity in exchange rates. We explore this link, arguing that the breakdown in the term structure and exchange rate theories are most probably driven by the same source - that is, short-term rates.

We are not the first paper to explore the links between the term structure and exchange rates. ${ }^{2}$ Our contribution is to exploit the information in the forward curve about future interest rates and exchange rates, and it is thus perhaps not a complete surprise that our conclusions differ markedly from these other papers. ${ }^{3}$

Our study has several important results. First, in contrast to current research on uncovered interest rate parity, past forward interest rate differentials have strong forecasting power for exchange rates. $\mathrm{R}^{2} \mathrm{~s}$ at some horizons exceed $20 \%$ for annual exchange rate changes relative to about $5 \%$ for the traditional specification. Moreover, the direction of these forecasts coincides with fundamental economic intuition, and imposing the theoretically motivated coefficient generates out-of-sample forecasts that outperform the random walk. Second, consistent with existing research, these same forward rates forecast both future expected spot rates and inflation, thus providing support for a fundamentally consistent economic framework. Third, the breakdown of uncovered interest rate parity derives from a negative relation between future exchange rate changes and the component of interest rates changes outside the above fundamentals.

This paper is organized as follows. Section II introduces the data. Section III describes the exchange rate parity relation in terms of forward rate differentials, and presents the surprising evidence favoring the exchange rate expectations hypothesis. In Section IV, we derive the link between the expectations hypothesis of interest rates and the expectations hypothesis of exchange rates by decomposing interest rate differentials into their expected component and their innovation. We argue that the failure of the exchange rates expectations hypothesis is due to the unexpected component of interest

\footnotetext{
${ }^{2}$ See, e.g., Campbell and Clarida (1987), Bekaert and Hodrick (2001), Bekaert, Wei, and Xing (2002), and Chinn and Meredith (2005).

${ }^{3}$ Chinn and Meredith (2005) are an exception in that they find support for uncovered interest parity using long-horizon exchange rate changes.
} 
rates. In Section V, we measure the robustness of our results in an out-of-sample forecasting exercise. Section VI concludes.

\section{Data}

We use monthly data from Datastream on exchange rates, inflation rates, and interest rates for the United States, the United Kingdom, and Germany from January 1976 to December 2003, a total of 336 months. Data for exchange rates (the Euro was substituted for the Deutschmark in the latter part of the sample) and CPI levels is available for the full period. Data for the term structure of zero-coupon interest rates is derived from LIBOR data (with maturities of six and twelve months) and swap rates (two-, three-, four-, and five-year semi-annual swap rates). ${ }^{4}$ Since swap data only become available in the late 1980s, we augment our zero curve data with data from Philippe Jorion. Jorion and Mishkin (1991) collect and derive data for zero coupon bonds from one month to five years for the United States, United Kingdom, and Germany from August 1973 to December $1988 .^{5}$ Swap and LIBOR data is preferred to typical government bond data because the quotes are more liquid and less prone to missing data, supply and demand effects, and tax-related biases. To the extent there is a swap spread in swap data, its effect is diminished by using interest rate differentials across countries in the majority of our analysis.

Using the exchange rate and CPI data described above, we compute annual changes in log exchanges rates with the U.S. dollar as the base currency, i.e., we examine changes in the USD/GBP and USD/DEM rates, and annual log changes in the CPI indexes, i.e., the inflation rates for the three countries. Given the monthly frequency of the underlying data, these annual changes have an 11-month overlap. Using the zero curve data, we compute continuously compounded one-year spot interest rates and one-year forward interest rates for each country from years 1 to 2,2 to 3,3 to 4 , and 4 to 5 . Our analysis

\footnotetext{
${ }^{4}$ Cubic spline functions were fitted each month for each country to create a zero curve for maturities of $6,12,18, \ldots, 60$ months. Our spline function fits the available data exactly, namely LIBOR rates for the 6-month and 12-month maturities, and semi-annual swap rates for maturities of 24 months, 36 months, 48 months, and 60 months. Therefore, the only maturities we need to spline are 18 months, 30 months, 42 months and 54 months. We maximize the smoothness of the spline function over these unknowns by minimizing the sum of squared deviations.

${ }^{5}$ We thank Philippe Jorion for graciously providing us with the data.
} 
matches the $j$ to $j+1$ forward interest rate at time $t$ with the subsequent exchange rate change from time $t+j$ to time $t+j+1$. To ensure that we use exactly the same exchange rate series for all regressions, we eliminate the first four years of the exchange rate data, truncating the interest rate series correspondingly. The final dataset consists of annual exchange rate changes from 1980 to 2003 (288 observations sampled monthly), spot interest rates over the same period, and forward interest rates over the periods 19792002, 1978-2001, 1977-2000, and 1976-1999 for horizons $j=1, \ldots, 4$, respectively (all with 288 observations). Tables $1 \mathrm{~A}$ and $1 \mathrm{~B}$ contain descriptive statistics for these variables.

\section{Uncovered Interest Rate Parity and the Expectations Hypothesis}

\section{A. Existing Evidence}

The expectations hypothesis for exchange rates is commonly written as

$$
E_{t} s_{t+j}=f_{t}^{j}
$$

where $s_{t+j}$ is the $\log$ of the spot price of foreign currency at time $t+j$, and $f_{t}^{j}$ is the $\log$ of $j$-period forward exchange rate at time $t$. Assuming no arbitrage and covered interest rate parity (i.e., $f_{t}^{j}-s_{t}=i_{t, j}-i_{t, j}^{*}$, where $i_{t, j}$ is the domestic $j$-period interest rate at time $t$ and the superscript $*$ denotes the corresponding foreign interest rate), the expected change in the exchange rate equals the interest rate differential. Thus, one standard way of testing equation (1) for $j=1$ is to estimate the regression

$$
\Delta s_{t, t+1}=\alpha+\beta d i_{t, 1}+\varepsilon_{t, 1},
$$

where $\Delta s_{t, t+1} \equiv s_{t+1}-s_{t}$ and $d i_{t, 1} \equiv i_{t, 1}-i_{t, 1}^{*}$. Under uncovered interest rate parity, $\alpha$ and $\beta$ should be 0 and 1 respectively. This hypothesis, and therefore equation (1), has been resoundingly rejected. The forward premium, $f_{t}^{k}-s_{t+k}$, has a systematic bias (i.e., $\alpha$ differs from zero), is predictable, and, most alarming, diverges, in that $\beta$ tends to be negative. ${ }^{6}$

\footnotetext{
${ }^{6}$ See, e.g., Engel (1996) and Lewis (1995) for surveys of this literature.
} 
A recent exception to these findings can be found in Chinn and Meredith (2005). They run regression equation (2) over long horizons, i.e., $\Delta s_{t, t+j}$ on $d i_{t, j}$, where $j$ varies from five to ten years. Using the last 20 years of data, and across many countries, the point estimates of $\beta$ tend to be positive, and are statistically indistinguishable from 1 . The statistical properties of the regressions, however, are questionable, as there are only two to four non-overlapping observations in the data. The problems with such regressions are well known. Richardson and Stock (1989) and Valkanov (2003) show that the estimators and test statistics are inconsistent, with non-normal limiting distributions. The intuition is that the frequent sampling of large partial sums of the data (i.e., in this case, five- to tenyear exchange rate movements) generates a series that takes on the properties of a nonstationary series, and standard central limit theorems no longer apply.

One way to avoid this problem is to use an alternative methodology based on a specified vector autoregression (VAR), which exploits short-run dynamics to infer longrange forecasts. ${ }^{7}$ The effectively small sample size issue motivates Bekaert, Wei, and Xing (2002) to look at the long-horizon properties of uncovered interest rate parity using VARs. However, there are two problems with this approach in the context of equation (2). First, as is well known from the predictability literature, the benefits underlying the VAR methodology quickly erode if the predictor variables are highly persistent. As has been documented elsewhere, and as is also apparent in Table 1A, the interest rate differentials have a high degree of serial correlation. Second, and more important, the VAR specification imposes a particular model on the system at hand. If that model is incorrect, then it is unclear how to interpret long-range forecasts. For the exchange rate and term structure hypotheses, there is ample evidence that the short and long runs behave quite differently. ${ }^{8}$ As pointed out by Fama (1984a) and in our findings to follow on exchange rates, it is this divergence that is most interesting.

As a first pass at the short-horizon version of equation (2), Table 1C reports estimates from regressions with annual exchange rate changes on a monthly overlapping basis. The $\beta$ coefficients are -1.30 and -0.98 for the USD/GBP and USD/DEM respectively,

\footnotetext{
${ }^{7}$ See, e.g., Hodrick (1992), and, more recently in the context of exchange rates and the term structure, Bekaert, Wei, and Xing (2002).
} 
confirming the well-known negative relation between exchange rates and interest rate differentials. While the estimates are fairly noisy, tests of the null hypothesis that the coefficients equal 1 can be resoundingly rejected.

The low $\mathrm{R}^{2} \mathrm{~s}$ in the regressions are notable, and this feature is both disappointing and puzzling. The key fundamentals underlying expected exchange rate movements are interest rate differentials between countries. These interest rate differentials, in theory, represent expected inflation rate differentials. Since inflation is fairly predictable (see, e.g., Fama and Gibbons (1984)), and inflation differentials are a fundamental driver of exchange rates via purchasing power parity, one would have expected the model to explain a much larger degree of the variation.

\section{B. Information about Exchange Rate Changes in Long-Maturity Forward Rates}

We can also use equation (1) to define expected changes in future exchange rates as the difference between two forward exchange rates. That is,

$$
E_{t}\left[\Delta s_{t+j, t+k}\right]=f_{t}^{k}-f_{t}^{j},
$$

where $k>j$. Under the expectations hypothesis, the period $t$ expected depreciation from $t^{t+j}$ to $t+k$ equals the difference in the corresponding forward rates at time $t$. Under covered interest rate parity, we can replace the forward exchange rates in equation (3) with the interest rate differentials between the two countries, i.e.,

$$
E_{t}\left[\Delta s_{t+j, t+k}\right]=d i_{t, k}-d i_{t, j} .
$$

Rearranging the interest rate differential terms in equation (4), and using the definition of forward interest rates, we get

$$
\begin{aligned}
E_{t}\left[\Delta s_{t+j, t+k}\right] & =\left(i_{t, k}-i_{t, j}\right)-\left(i_{t, k}^{*}-i_{t, j}^{*}\right) \\
& =i f_{t}^{j, k}-i f_{t}^{* j, k} \equiv d i f_{t}^{j, k},
\end{aligned}
$$

where $i f_{t}^{j, k}$ and $i f_{t}^{* j, k}$ are the forward interest rates at time $t$ from $t+j$ to $t+k$ for domestic and foreign currencies, respectively. Equation (5) is the basis for much of the empirical

\footnotetext{
${ }^{8}$ Consider, e.g., the findings in Fama (1984) and Fama and Bliss (1987).
} 
analysis to follow. It says that the expected depreciation in future exchange rates is equal to $\operatorname{dif}_{t}^{j, k}$, what we call the forward interest rate differential.

Equation (5) extends the classical approach to characterizing and testing the expectations hypothesis presented in equations (1) and (2). It implies a more general specification of the expectation hypothesis,

$$
\Delta s_{t, t+1}=\alpha+\beta d i f_{t-j}^{j, j+1}+\varepsilon_{t-j, j+1} .
$$

Under the expectations hypothesis of exchange rates, the exchange rate change from $t$ to $t+1$ should move one-for-one with the forward interest rate differential from $j$ to $j+1$ that was set at time $t-j$. That is, $\alpha$ and $\beta$ should equal 0 and 1 respectively. Equation (2) is a special case of equation (6) for $j=0$.

Equation (6) exploits the information in the entire forward curve. However, the error term is now a $j$-step ahead forecast, and therefore is serially correlated up to $j$ observations. ${ }^{9}$ Standard techniques can adjust for this type of dependence. ${ }^{10}$

One of the difficulties in studying multi-step ahead forecast regressions like those specified in equation (6) is the availability of data. While sophisticated econometrics have somewhat alleviated the problem, ${ }^{11}$ the benefits are still constrained by the number of independent observations (see the discussion in Section III.A above). However, for the regression in equation (6), the degree of serial correlation in the errors depends upon the relative variance of exchange rates versus interest rate differentials, and the correlation of unexpected shocks to these variables. There are strong reasons to suspect that these factors mitigate the serial correlation problem. Table 1A shows that exchange rates are much more variable than interest rate differentials, and are relatively unpredictable. Therefore, because the forecast update component of the residual in equation (6) is likely to be small relative to the unpredictable component as we move forward in time, the induced serial correlation in the errors will be correspondingly small, and the overlap will not substantially reduce the effective number of independent observations. This intuition is confirmed through our simulation.

\footnotetext{
${ }^{9}$ In our case, $j$ is measured in years and the data is sampled monthly, so the overlap will be $12 * j$.

${ }^{10}$ See, e.g., Hansen and Hodrick (1980) and Hansen (1982).

${ }^{11}$ See, e.g., Hansen (1982), Newey and West (1987), and Andrews (1991).
} 
Table 2 describes estimates over different horizons and across different currencies for tests of the expectations hypothesis of exchange rates through equation (6). In contrast to Table 1C and the conclusions in much of the literature, Table 2 shows that forward interest rate differentials can predict changes in future exchange rates. At least as important is that their predictive power has the right sign. The U.S./Germany forward differentials of one to four years yield coefficients of $0.57,0.86,2.50$, and 3.50 for the USD/DEM exchange rate. The results for the USD/GBP exhibit a similar pattern, with coefficients of $1.08,4.27,2.34$, and 3.18 looking forward one to four years, respectively. Given the noise in the forward interest rate data, we also report the coefficient from regressing exchange rate changes on the average of the four forward interest rate differentials (i.e., $\frac{1}{4} \sum_{j=1}^{4} d i f_{t-j}^{j, j+1}$ ) with coefficients of 5.78 and 2.82 for the USD/GBP and the USD/DEM respectively. Since the theory predicts a coefficient of 1 , these results are quite different from those in Table 1C; interestingly, the estimates follow a similar pattern to those in the term structure regressions discussed below.

The coefficient estimates, while of the correct sign, are noisy. However, as Table 2B reports, joint tests of the hypothesis that $\beta=1$ at each horizon across the currencies yields one rejection $(j=2)$ and three non-rejections $(j=1,3$, and 4$)$ at the $5 \%$ level using the Wald test. None of the four Lagrange multiplier (LM) tests generate rejections at the 5\% level, with p-values ranging from $6 \%$ to $92 \%$. ${ }^{12}$ Table $2 \mathrm{~B}$ also documents tests across horizons for a given currency and across currencies. Testing the null hypothesis of $\beta=1$ across horizons $j=1,2,3$, and 4 (but not $j=0$ ), the LM test does not reject the null for either currency, and the Wald test rejects it for the USD/GBP. Across currencies, the Wald test again rejects, but the LM test does not. These results starkly contrast those for the oneyear horizon $(j=0)$, which generate rejections of uncovered interest rate parity for both tests and a restricted coefficient estimate of -1.08 .

\footnotetext{
${ }^{12}$ Throughout this study, we employ both the Lagrange multiplier and Wald statistics for testing the joint hypotheses. As shown by Berndt and Savin (1977), there is a numerical ordering between these statistics, which may lead to different inferences being drawn. For an especially relevant discussion, see Bekaert and Hodrick (2001) in the context of testing the expectations hypothesis of the term structure. In their context, the Wald test over-rejects while the Lagrange multiplier test under-rejects.
} 
Note in Table 2 that the regression $\mathrm{R}^{2}$ s increase as the horizon increases. While the dependent variable, i.e., annual exchange rate changes, is the same, the forecasting variable differs. For the USD/DEM, the $\mathrm{R}^{2} \mathrm{~s}$ are higher for three out of four of the forward interest rate differential regressions (equation (6)) than for the interest rate differential regression (equation (2)). What is remarkable about this result is that the information in the former regressions is (i) old relative to current interest rates, and (ii) more subject to measurement error due to the calculation of forward rates. We argue below that this finding is a direct result of the fundamental relation between exchange rates, inflation, and interest rates, and the puzzling behavior of short-term interest rates.

One potential concern is that the $\mathrm{R}^{2} \mathrm{~s}$ are spuriously high due to small sample problems in the longer horizon regressions. We argue above that the overlap problem is not that serious due to the relatively low predictability of exchange rate changes, but it is still important to verify this conjecture. Consequently, we construct a Monte Carlo experiment in which we estimate a VAR for the relevant forward rate differentials, interest rate differentials, and changes in exchange rates, imposing the expectations hypotheses in both interest rates and exchange rates. We then simulate this model, assuming that the residuals follow a multivariate normal distribution. We generate 100,000 replications of 24 annual observations. For each replication, we estimate equation (6) and the long-horizon regression version of equation (2) following Chinn and Meredith (2005). Table 3 reports the resulting distribution of the parameter estimates and test statistics. (The experiment itself is detailed in Appendix A.)

Table 3A compares the regression in equation (6) to the long-horizon version of the regression in equation (2). When one uses equation (6), the biases are less severe, and there appears to be much more independent information. While the $\beta$ estimates are somewhat similar between the two approaches (with a slight downward bias), the $\mathrm{R}^{2} \mathrm{~s}$ are much more biased using regression (2), especially for long horizons. As the horizon goes from one to four years, the bias increases from $3.28 \%$ to $4.08 \%$ for regression (6), versus an increase from $4.85 \%$ to $7.18 \%$ for regression (2). Equally problematic for the regressions based on equation (2), the correlations between the estimators range from 0.53 to 0.94 across the various horizons, in contrast to only 0.25 to 0.76 for the 
regressions in equation (6). In short, there is considerably more independent information in the latter regression system. In general, however, these simulation results suggest that small sample bias cannot explain the large differences in $\mathrm{R}^{2} \mathrm{~s}$ across horizons found in the data.

Table 3C presents simulation results for the Wald and Lagrange multiplier tests for the regressions in equation (6) across the horizons. As expected, the Wald test substantially over-rejects, and the LM test substantially under-rejects, the null hypothesis. The problem with the Wald test is much worse for the hypothesis $\beta_{j}=1$, but the LM test performs similarly for both hypotheses. Therefore, these results more strongly support the expectations hypothesis in light of the Wald and Lagrange statistics reported in Table 2.

\section{Exchange Rates, Interest Rates, and Inflation Rates: Fundamentals and the Expectations Hypothesis}

\section{A. The Expectations Hypothesis of Interest Rates across Countries}

A related literature investigating the expectations hypothesis of interest rates has evolved similarly to the exchange rate literature. According to the expectations hypothesis of interest rates, forward interest rates equal future expected spot rates:

$$
E_{t} i_{t+j, 1}=i f_{t}^{j, j+1} \text {. }
$$

Analogous to the exchange rate literature, the standard way of testing equation (7) is to regress the change in interest rates on the forward interest rate premium (i.e., if- $i$ ). That is,

$$
i_{t+j, 1}-i_{t, 1}=\alpha+\beta\left(i f_{t}^{j, j+1}-i_{t, 1}\right)+\varepsilon_{t, j} .
$$

Under the expectations hypothesis, $\alpha$ and $\beta$ should be 0 and 1 , respectively.

This literature commonly finds that the expectations hypothesis works poorly at short horizons, both in terms of explanatory power and the sign and magnitude of the $\beta$ coefficient. ${ }^{13}$ However, the relation appears to hold much better at longer horizons. Table 4 replicates the regression analysis in Fama and Bliss (1987) and Jorion and

\footnotetext{
${ }^{13}$ See, e.g., Fama (1984a), Bekaert and Hodrick (2001).
} 
Mishkin (1991) of future spot interest rates on forward interest rates across the United States, United Kingdom, and Germany for our sample period.

Over the period 1964 to 1984, Fama and Bliss document coefficients of 0.09, 0.69, 1.30, and 1.61 for changes in 1-year rates on 1-year forwards 1 to 4 years prior, respectively. Although our sample covers the period 1980 to 2003, our results are very similar. In the U.S. data, the analogous coefficients for 1 -year forwards 1 to 4 years prior are $0.00,0.13,0.70$, and 1.16. We see a similar pattern for the U.K. data, with coefficients of $0.47,1.00,1.18$, and 1.40, coinciding with the findings of Jorion and Mishkin (1991), whose sample ends in 1987.

One of the major findings of Fama and Bliss (1987) is that the $\mathrm{R}^{2}$ also increases dramatically with the horizon, notably from $0 \%$ and $0.3 \%$ in the shorter horizons of $j=1$ and 2, to $7 \%$ and $19 \%$ for the 3- and 4-year horizons. Fama and Bliss suggest that this result arises from interest rates following a slow mean-reverting process. Under this scenario, the variance of the expected interest rate change become a more important component of the overall variability of interest rate changes as the horizon increases, consistent with their finding. An alternative explanation is that a wedge between short and long horizons accounts for the failure of the expectations hypothesis. If short-term rates are governed not only by underlying fundamentals, but are also a function of policy variables (e.g., central banks' policies affecting inflation or exchange rates via the short rate), then distortions are likely to occur.

As can be seen from Table 4 , the $\mathrm{R}^{2} \mathrm{~s}$ increase with the horizon for all three countries. The increase for $j=1$ to $j=4$ for the United States is $0 \%$ to $19 \%$; for the United Kingdom, $9 \%$ to $46 \%$; and for Germany, $6 \%$ to $50 \%$. The magnitude of the coefficients and the higher $\mathrm{R}^{2} \mathrm{~s}$ suggest that there is considerable information in long-maturity forwards about expected future interest rates. Since the differences in these interest rates in theory forecast future exchange rate movements under uncovered interest rate parity, there appears to be some hope that we can address the forward premium puzzle. The next section deals with this question. 


\section{B. The Relation Between the Expectations Hypothesis of Interest Rates and Exchange Rates}

The above results pose a puzzle to researchers studying the expectations hypothesis of the term structure and exchange rates. On one hand, the results using past forward interest rate differentials differ from those using current interest rate differentials. On the other hand, there is considerable evidence that long-maturity forwards forecast future interest rates, which, in turn, should reflect the predictive component of exchange rate movements. It seems worthwhile, therefore, to separate these effects to further understand why we so soundly reject the theory in one case and accept it in another.

Equations (2) and (6) can be linked through the expectations hypothesis of interest rates as described in equation (7). Under this hypothesis, the forward interest rate differential is related to the expected future spot interest rate differential:

$$
d i f_{t}^{j, k}=E_{t}\left[d i_{t+j, k-j}\right] .
$$

Equation (9) implies that the interest rate differential $d i_{t+j, k-j}$ can be broken into its expected component, dif $f_{t}^{j, k}$, and its unexpected component, which we denote $u_{t, j}^{k-j}=d i_{t+j, k-j}-d i f_{t}^{j, k}$. The unexpected component is the $j$-step ahead forecast error of a $(k-j)$-period interest rate. For $k-j=1$, and combining the above breakdown with equation (2), we obtain the regression:

$$
\Delta s_{t, t+1}=\alpha+\beta d i f_{t-j}^{j, j+1}+\gamma u_{t-j, j}^{1}+\varepsilon_{t-j, j+1} .
$$

Under the expectations hypothesis of exchange rates, $\alpha$ should equal 0 , and both $\beta$ and $\gamma$ should equal 1. By separating out the $\beta$ and $\gamma$ coefficients, the expectations hypothesis of the term structure allows us to understand the source of the forward premium anomaly in equation (2).

At first glance, it may seem that using the expectations hypothesis of the term structure is misguided. After all, as mentioned above, this hypothesis has been soundly rejected in a variety of contexts. However, the precise formulation of the hypothesis in equation (9) used in equation (10) relates forward rates to future spot rates of interest. Whether forward interest rates forecast future spot interest rates is a much-studied topic. The literature and the results in Table 4 suggest that the forecasts work poorly at short 
horizons, but quite well at long horizons. Regression equation (10) lets us separate out the term structure expectations effect by running the multiple regression of exchange rate moves on both (i) the difference between the interest rate and forward interest rate differential and (ii) the forward rate differential itself.

Table 5 contains results for this regression for each exchange rate and horizon. Because the forward interest rate differentials can be quite noisy at any given horizon, we again examine, in addition, a regression with the average past forward rate differential, i.e., $\frac{1}{4} \sum_{j=1}^{4} d i f_{t-j}^{j, j+1}$, which should also have a coefficient of 1 . Across all of the horizons (including the average horizon) and across both currencies, the coefficient $\beta$ is always positive for the USD/GBP and USD/DEM, hovering (albeit noisily) around 1. In contrast, the $\gamma$ coefficients are all negative and of similar magnitude. The $\mathrm{R}^{2} \mathrm{~s}$ are quite impressive.

For the USD/DEM exchange rate, at forward rate horizons of one to four years, the $\beta \mathrm{s}$ are $0.53,0.31,1.58$, and 2.49 , respectively, while the $\gamma$ s are $-2.79,-1.38,-1.28$, and 1.11. Similarly, for the average forward rate, $\beta$ is 2.54 and $\gamma$ is -2.03 with an $\mathrm{R}^{2}$ of $20 \%$. Table 5 documents that the same forecast power of forward rates for future interest rates is also present in forecasting future exchange rate changes.

The negative $\gamma$ explains why the forward premium anomaly exists from a statistical viewpoint - that is, why we get negative coefficients and low $\mathrm{R}^{2} \mathrm{~s}$ in Table 1. Breaking up current interest rates into the two components separates out the "fundamental" information contained in the forward curve from other, unspecified, information. The fundamental information by and large conforms to the expectations hypothesis of the term structure and the expectations hypothesis of exchange rates, while this other information does not. Including them together, the two information sources offset each other, leading to a low $\mathrm{R}^{2}$.

From an economic standpoint, the puzzle is why the coefficient on the interest rate differential in the exchange rate regression is negative. If the additional information in the interest rate differential (relative to the forward rate differential) is just noise-if it is uncorrelated with future exchange rate changes - then the coefficient should simply be biased towards zero. A negative coefficient suggests that this information is negatively 
correlated with the relevant fundamental information, but this issue is beyond the scope of this paper. The next subsection sheds light on one source for this fundamental information, namely, expected inflation.

\section{Inflation Rates and Fundamentals}

Inflation is a major fundamental factor in determining the exchange rate, so one obvious relation to examine is the link between forward interest rates and inflation. Table 6 shows results from regressions of the future change in inflation on the spread between the forward interest rate and the spot rate across countries and horizons. The specification is similar to equation (8), with changes in the rate of inflation as the dependent variable:

$$
\pi_{t+j, 1}-\pi_{t, 1}=\alpha+\beta\left(i f_{t}^{j, j+1}-i_{t, 1}\right)+\varepsilon_{t, j} .
$$

At longer horizons, changes in inflation move approximately one-for-one with forward rate differentials. Moreover, $\mathrm{R}^{2} \mathrm{~s}$ also increase substantially as we move to longer horizons. ${ }^{14}$ These results are consistent with the interest rate expectations hypothesis regressions in Table 4, suggesting that those previous regression results are potentially driven by inflation predictability, or lack thereof, when using interest rates and forward rates at different horizons.

Put together, our empirical results suggest a positive relation between forward interest rate differentials and both (i) future changes in exchange rates, and (ii) inflation rate differentials. In other words, over long horizons, both the expectations hypothesis of interest rates and the analogous theories for inflation and exchange rates conform well to the data. This is precisely what one would expect to emerge from standard economic models, if one had never heard of the forward premium anomaly.

While we have not resolved the forward premium puzzle in its entirety (e.g., consider the short-horizon results and the negative $\gamma$ coefficients in Table 5), our results are instructive in the context of the current literature. There are two important features to our findings: (i) there is a breakdown between the short- and long-term in all of the cases

\footnotetext{
${ }^{14}$ Jorion and Mishkin (1991) report similar results for an earlier sample period.
} 
discussed above, and (ii) the common element appears to be the "failure" of short-term interest rates to conform to the theory.

Two popular (albeit unsuccessful) explanations for the forward premium puzzle are the existence of risk premia or errors in expectations - either statistical issues, such as peso problems, or behavioral phenomena, such as violations of rational expectations. ${ }^{15}$ The breakdown between short and long horizons appears to impose an even greater burden on these theories to explain the data. Since uncovered interest rate parity is based upon the equality of ex ante real rates across countries, perhaps a more fruitful avenue of research can be found in the exchange rate literature on market failures, such as segmentation in the asset market (e.g., Alvarez, Atkeson, and Kehoe (2002)), frictions in the goods market and liquidity (e.g., Lucas (1982) and McCallum (1994)), or limited arbitrage in the foreign exchange market (e.g., Froot and Thaler (1990)). All of these papers are consistent with interest rates as the source of short-term deviations from fundamentals, a necessary component to match our empirical findings.

\section{Robustness}

\section{A. Contemporaneous Forward Differentials}

We argue that dated (i.e., old) information in forward rate differentials is important because these differentials predict the fundamental component of future changes in exchange rates. An alternative story is that there is simply additional information in the term structure of interest rates about future exchange rates that has nothing to do with fundamentals. If this were the case, then presumably forward interest rates contemporaneous with the spot rates in the standard forward premium regression would provide better information than lagged differentials, since they contain newer information.

Table 7 investigates this conjecture via estimation of the regression

$$
\Delta s_{t, t+1}=\alpha+\beta\left[\frac{1}{4} \sum_{j=1}^{4} d i f_{t}^{j, j+1}\right]+\gamma u_{t, a v g}+\varepsilon_{t-j, j+1},
$$


where $u_{t, \text { avg }}=d i_{t, 1}-\frac{1}{4} \sum_{j=1}^{4} d i f_{t}^{j, j+1}$. These regressions are analogous to those presented above under the label "avg" in Table 5 (i.e., estimates from equation (10)), except that the regressor is the average of contemporaneous (time $t$ ) forward rates instead of lagged forward rates. The notable result is that the $\mathrm{R}^{2} \mathrm{~s}$ of these regressions are extremely low, namely, $5.90 \%$ and $4.28 \%$, versus $28.30 \%$ and $19.58 \%$ for the regressions using lagged forward rate differentials in Table 5 . The predictive power is only a little higher than it is when using the current spot interest rate differential alone (see Table 2). These results confirm the validity of the economic-based story developed above. The innovation in current forward rates relative to lagged rates reduces their power to explain exchange rate changes.

\section{B. Out-of-Sample Prediction}

Can our model beat the random walk model in an out-of-sample forecasting experiment? We compare the random walk model and the expectations hypothesis in its standard form (equation (2)) to using the forward interest rate differential, appropriately lagged. ${ }^{16} \mathrm{We}$ impose the null hypothesis of $\beta=1$, rather than using any dynamic estimation, and compute root mean squared errors as is common in this literature, with the random walk as the benchmark. A full description of the out-of-sample experiment and the corresponding statistical methodology based on Diebold and Mariano (1995) appears in Appendix B. ${ }^{17}$

The results, presented in Table 8, show that, for both currencies, uncovered interest parity, i.e., using the spot rate differential, fails to beat the random walk hypothesis. This is consistent with extant empirical results. In fact, consistent with the negative sign in the

\footnotetext{
${ }^{15}$ See, e.g., Fama (1984b) and Bekaert (1996) for risk premia explanations. For the former type of expectational errors, see Lewis (1995) for exchange rates and Bekaert, Hodrick, and Marshall (2001) for interest rates. For the latter, see Froot and Ito (1989).

${ }^{16}$ To keep the presentation complete we also examine the out of sample performance of the contemporaneous forward interest rate differential.

${ }^{17}$ Clark and West (2005) point out two circumstances in which the Diebold-Mariano approach will potentially generate misleading results: (1) when there is estimation error implicit in the forecast errors, and (2) when the models are nested. Neither applies in our case since we impose the theoretical coefficients.
} 
in-sample regression on interest rate differentials, the out-of-sample $\mathrm{R}^{2} \mathrm{~s}$ are negative and the p-values lie in the tail of poor performance. In stark contrast, results for the forward interest rate differential are much more consistent with theory. For each currency separately, and at every horizon, the forward interest rate differential beats the random walk model, albeit by small amounts, especially for the USD/DEM exchange rate. While the marginal explanatory power is significant at the $5 \%$ level for only one of the horizons, the average across horizons has a p-value of 0.07 for the USD/GBP exchange rate. Using the current forward interest rate differential, and thus not the one implied by theory (see Section V.A above), the out-of-sample $\mathrm{R}^{2} \mathrm{~s}$ are negative and lead to greater root mean squared errors than the random walk.

What is particularly interesting about these findings is that old information, i.e., past forward interest rate differentials, outperforms both the random walk model and models that employ current spot or forward rate differentials. This result suggests that the appropriate updates to these past, theory-implied, forward rate differentials may add further to our ability to forecast exchange rate movements.

\section{Concluding Remarks}

Forward interest rates forecast future spot interest rates and inflation rates, and differentials of these forward rates forecast movements in exchange rates. The forecasts are in the direction consistent with the international Fisher effect, the expectations hypothesis of the term structure, and uncovered interest rate parity, respectively. That these fundamental relations hold is good news for financial economics. Of course, the breakdown in interest rate parity must be coming from somewhere, and this paper points to two possible future areas of investigation. The first relates to our identification of fundamentals through stale information, i.e., past forward interest rate differentials. Updating these estimates using current information should tighten the relation. Second, the source of the forward premium anomaly appears to be the anomalous behavior of short-term interest rates. Since these fundamental theories have at their core some notion of equality of ex ante real rates across countries, the difference in these real rates, both empirically and possibly theoretically, seems like a good place to start. 


\section{Appendix A: Simulation of Uncovered Interest Rate Parity}

For the simulation experiment, we assume that the expectations hypotheses of exchange rates and interest rates hold at an annual frequency, and that the longest maturity forward rate (4 to 5 years) follows an AR(1) process:

$$
\begin{aligned}
& \Delta s_{t, t+1}=d i_{t, 1}+\varepsilon_{t, t+1}^{s} \\
& d i_{t+1,1}=d i f_{t}^{1,2}+\varepsilon_{t, t+1}^{1} \\
& d i f_{t+1}^{1,2}=d i f_{t}^{2,3}+\varepsilon_{t, t+1}^{2} \\
& d i f_{t+1}^{2,3}=d i f_{t}^{3,4}+\varepsilon_{t, t+1}^{3} \\
& d i f_{t+1}^{3,4}=d i f_{t}^{4,5}+\varepsilon_{t, t+1}^{4} \\
& d i f_{t+1}^{4,5}=\rho d i f_{t}^{4,5}+\varepsilon_{t, t+1}^{5}
\end{aligned}
$$

where

$$
\varepsilon_{t, t+1} \equiv\left[\begin{array}{c}
\varepsilon_{t, t+1}^{s} \\
\varepsilon_{t, t+1}^{1} \\
\varepsilon_{t, t+1}^{2} \\
\varepsilon_{t, t+1}^{3} \\
\varepsilon_{t, t+1}^{4} \\
\varepsilon_{t, t+1}^{5}
\end{array}\right] \sim M V N(0, \Sigma)
$$

We estimate the parameters of this model ( $\rho$ and $\Sigma$ ) using the U.S. and U.K. data, although the conclusions are essentially identical using U.S. and German data.

Define the state vector

$$
y_{t+1}=\left[\begin{array}{c}
\Delta s_{t, t+1} \\
d i_{t+1,1} \\
d i f_{t+2}^{1,2} \\
d i f_{t+1}^{2,3} \\
d i f_{t+1}^{3,4} \\
d i f_{t+1}^{4,5}
\end{array}\right]
$$

Equation (13) implies that $y_{t+1} \sim M V N(0, \Omega)$, where $\Omega$ is a function of $\rho$ and $\Sigma$. The simulation procedure is as follows:

1. Draw starting values $y_{t}$ from the distribution $y_{t} \sim M V N(0, \Omega)$. 
2. Draw an error vector $\varepsilon_{t+1}$ from the distribution $\varepsilon_{t+1} \sim M V N(0, \Sigma)$.

3. Compute $y_{t+1}$ using this error vector and the lagged state vector via equation (13).

4. Return to step 2 above.

We generate 100,000 simulations of 24 annual observations, the length of our sample. For each sample, we estimate equation (6) and compute various test statistics. We also estimate the long-horizon versions of the regression in equation (2), after Chinn and Meredith (2005). The results appear in Table 3.

\section{Appendix B: Out-of-Sample Testing}

We apply the methodology introduced by Diebold and Mariano (1995), using the squared error of the models as our loss function. Define the loss differential as

$$
d_{t}=e_{i t}^{2}-e_{j t}^{2},
$$

where $e_{i t}$ and $e_{j t}$ are the forecast errors from competing models for period $t$. We use the random walk model as the benchmark (model $i$ ) and all models are compared against it. We impose uncovered interest rate parity or forward interest rate differential parity; therefore, no estimation is required. For the lagged forward interest rate differential as a predictor, the forecast errors for the two models are

$$
\begin{aligned}
& e_{i t}=\Delta s_{t, t+1} \\
& e_{j t}=\Delta s_{t, t+1}-d i f_{t-j}^{j, j+1} .
\end{aligned}
$$

We then test the hypothesis $E\left[d_{t}\right]=0$ versus the alternative $E\left[d_{t}\right]>0$, i.e., that the proposed model is better than the random walk model. The mean of the loss differential is estimated via the generalized method of moments, and the associated test statistic, which has an asymptotic $\mathrm{N}(0,1)$ distribution, is adjusted for serial correlation in the loss differential series. We also report the root mean squared error for each model, the $\mathrm{R}^{2}$ from the associated in-sample regression (from Tables 2 and 6), and the out-of-sample $\mathrm{R}^{2}$, defined as 


$$
R^{2}=1-\left(\frac{\sum_{t=1}^{T} e_{j t}^{2}}{\sum_{t=1}^{T} e_{i t}^{2}}\right),
$$

where $e_{i t}$ are the forecast errors from the random walk model and $e_{j t}$ are the forecast errors from the alternative model. This quantity is computed using the second moments, not the variances of the forecast errors, i.e., there is no mean adjustment. 


\section{References}

Alvarez, F., A. Atkeson, and P.J. Kehoe, 2002, "Money, Interest Rates, and Exchange

Rates in Endogenously Segmented Markets," Journal of Political Economy 110, 73-112.

Andrews, D.W.K., 1991, "Heteroskedasticity and Autocorrelation Consistent Covariance Matrix Estimation," Econometrica 59, 817-854.

Bekaert, G., 1996, "The Time-Variation of Risk and Return in Foreign Exchange Markets: A General Equilibrium Perspective," Review of Financial Studies 9, 427-470.

Bekaert, G., and R.J. Hodrick, 2001, "Expectations Hypotheses Tests," Journal of Finance 56, 115-138.

Bekaert, G., M. Wei, and Y. Xing, 2002, "Uncovered Interest Parity and the Term Structure," NBER Working Paper No. 8795.

Bekaert, G., R. J. Hodrick, and D. Marshall, 2001, "Peso Problem Explanations for Term Structure Anomalies," Journal of Monetary Economics 48, 241-270.

Berndt, E.R., and N.E. Savin, 1977, "Conflict Among Criteria for Testing Hypotheses in the Multivariate Linear Regression Model," Econometrica 45, 1263-1277.

Campbell, J.Y., and R.H. Clarida, 1987, "The Term Structure of Euromarket Interest Rates: An Empirical Investigation," Journal of Monetary Economics 19, 25-44.

Cheung, Y.W., M. Chinn, and A. Garcia Pascual, 2003, "Empirical Exchange Rate Models of the Nineties: Are Any Fit to Survive?" NBER Working Paper No. 9393.

Chinn, M., and G. Meredith, 2005, "Testing Uncovered Interest Parity at Short and Long Horizons during the Post-Bretton Woods Era," NBER Working Paper No. 11077.

Clark, T.E., and K.D. West, 2005, "Using Out-of-Sample Mean Squared Projection Errors to Test the Martingale Difference Hypothesis," NBER Technical Working Paper 305.

Diebold, F.X., and R.S. Mariano, 1995, “Comparing Predictive Accuracy," Journal of Business and Economic Statistics 13, 253-263.

Engel, C., 1996, "The Forward Discount Anomaly and the Risk Premium: A Survey of Recent Evidence," Journal of Empirical Finance 3, 123-192.

Fama, E.F., 1984a, "The Information in the Term Structure," Journal of Financial Economics 13, 509-528. 
Fama, E.F., 1984b, "Forward and Spot Exchange Rates," Journal of Monetary

Economics 14, 319-338.

Fama, E.F., and R. Bliss, 1987, “The Information in Long Maturity Forward Rates," American Economic Review 77, 680-692.

Fama, E.F., and M. Gibbons, 1984, "A Comparison of Inflation Forecasts," Journal of Monetary Economics 13, 327-348.

Froot, K.A., and R.H. Thaler, 1990, "Foreign Exchange," Journal of Economic Perspectives 4, 179-192.

Froot, K.A., and T. Ito, 1989, "On the Consistency of Exchange Rate Expectations," Journal of International Money and Finance 8, 487-510.

Hansen, L.P., 1982, "Large Sample Properties of Generalized Methods of Moments Estimators," Econometrica 50, 1029-1054.

Hansen, L.P., and R.J. Hodrick, 1980, "Forward Exchange Rates as Optimal Predictors of Future Spot Rates: an Econometric Analysis," Journal of Political Economy 88, 829-853.

Hodrick, R.J., 1987, The Empirical Evidence on the Efficiency of Forward and Futures Foreign Exchange Markets. Harwood Academic Publishers, Chur, Switzerland.

Hodrick, R.J., 1992, "Dividend Yields and Expected Stock Returns: Alternative Procedures for Inference and Measurement," Review of Financial Studies 5, 357-386.

Jorion, P., and F. Mishkin, 1991, "A Multicountry Comparison of Term-Structure Forecasts at Long Horizons," Journal of Financial Economics 29, 59-80.

Lewis, K.K., 1995, Puzzles in International Finance, Handbook of International Economics. Volume 3. Grossman, Gene M. and Rogoff, Kenneth, eds., Handbooks in Economics, vol. 3. Amsterdam; New York and Oxford: Elsevier, North-Holland. 19131949.

Lucas, R., 1982, "Interest Rates and Currency Prices in a Two Country World," Journal of Monetary Economics 10, 335-359.

McCallum, B.T., 1994, "A Reconsideration of the Uncovered Interest Parity Relationship," Journal of Monetary Economics 33, 105-132.

Meese, R.A., and K. Rogoff, 1983, "Empirical Exchange Rate Models of the Seventies: Do They Fit Out of Sample?” Journal of International Economics 14, 3-24. 
Newey, W.K., and K.D. West, 1987, “A Simple Positive Semi-Definite,

Heteroskedasticity and Autocorrelation Consistent Covariance Matrix," Econometrica $51,1233-1242$.

Richardson, M., and J. Stock, 1989, "Drawing Inferences From Statistics Based on Multiyear Asset Returns," Journal of Financial Economics 25, 323-348.

Valkanov, R., 2003, "Long-Horizon Regressions: Theoretical Results and Applications," The Journal of Financial Economics 68, 201-232. 


\section{Table 1: Preliminaries}

Panel A: Summary Statistics - Exchange Rates

\begin{tabular}{ccccccc}
\hline $\begin{array}{c}\text { Exchange } \\
\text { Rate }\end{array}$ & $\begin{array}{c}\text { Mean } \\
(\%)\end{array}$ & $\begin{array}{c}\text { SD } \\
(\%)\end{array}$ & $\begin{array}{c}\text { 1st Order } \\
\text { Autocorr. }\end{array}$ & $\begin{array}{c}\text { 12th Order } \\
\text { Autocorr. }\end{array}$ & Correlations \\
\hline USD/GBP & -0.98 & 11.35 & 0.93 & 0.04 & 1 & 0.72 \\
USD/DEM & 0.59 & 13.42 & 0.94 & 0.15 & 0.72 & 1 \\
\hline
\end{tabular}

Panel B: Summary Statistics - Forward Rate Differentials

\begin{tabular}{cccccc}
\hline if $^{j, j+1}-i f^{* j, j+1}$ & $\mathrm{c}$ & $\begin{array}{c}\text { Mean } \\
(\%)\end{array}$ & $\begin{array}{c}\text { SD } \\
(\%)\end{array}$ & $\begin{array}{c}\text { 1st Order } \\
\text { Autocorr. }\end{array}$ & $\begin{array}{c}\text { 12th Order } \\
\text { Autocorr. }\end{array}$ \\
\hline US-UK & 0 & -1.85 & 2.11 & 0.95 & 0.55 \\
& 1 & -1.07 & 1.29 & 0.88 & 0.41 \\
& 2 & -1.21 & 1.39 & 0.91 & 0.50 \\
& 3 & -1.13 & 1.42 & 0.87 & 0.47 \\
& 4 & -1.28 & 1.53 & 0.89 & 0.51 \\
\hline US-Germ. & 0 & 1.32 & 2.54 & 0.98 & 0.76 \\
& 1 & 1.65 & 1.89 & 0.96 & 0.72 \\
& 2 & 1.79 & 1.60 & 0.96 & 0.70 \\
& 3 & 1.77 & 1.55 & 0.96 & 0.70 \\
& 4 & 1.65 & 1.64 & 0.97 & 0.72 \\
\hline
\end{tabular}

Panel C: The Forward Premium Puzzle - 1-Year Horizon

\begin{tabular}{lccccc}
\hline Exchange Rate & $\alpha$ & Std. Err. & $\beta$ & Std. Err. & $\mathrm{R}^{2}$ \\
\hline USD/GBP & -3.38 & 2.09 & -1.30 & 0.93 & 5.85 \\
USD/DEM & 1.88 & 2.31 & -0.98 & 0.77 & 3.42 \\
\hline
\end{tabular}

Panels A and B report summary statistics (mean, standard deviation, first-order autocorrelation, twelfthorder autocorrelation, and cross correlations) for annual changes in log exchange rates and 1-year forward interest rate differentials at various horizons, sampled monthly. Panel $\mathrm{C}$ reports coefficient estimates, corresponding standard errors (heteroscedasticity and autocorrelation adjusted), and $\mathrm{R}^{2} \mathrm{~s}$ from the forward premium regression at the 1-year horizon

$$
\Delta s_{t, t+1}=\alpha+\beta\left(d i_{t, 1}\right)+\varepsilon_{t, 1} .
$$

Exchange rate data cover 1980-2003 and interest rate data cover 1980-2003, 1979-2002, 1978-2001, 1977-2000, and 1976-1999 for horizons $j=0, \ldots, 4$, respectively, for a total of 288 monthly observations in all cases. See Section II for a detailed description of the data. 
Table 2: The Expectations Hypothesis of Exchange Rates

\begin{tabular}{lcccccr}
\multicolumn{7}{c}{ Panel A: Regression Results } \\
\hline Exchange Rate & $\mathrm{j}$ & $\alpha$ & Std. Err. & $\beta$ & Std. Err. & \multicolumn{1}{c}{$\mathrm{R}^{2}$} \\
& & & & & & \\
\hline USD/GBP & 0 & -3.38 & 2.09 & -1.30 & 0.93 & 5.85 \\
& 1 & 0.17 & 2.57 & 1.08 & 1.41 & 1.49 \\
& 2 & 4.18 & 1.84 & 4.27 & 0.74 & 27.20 \\
& 3 & 1.67 & 1.94 & 2.34 & 1.05 & 8.54 \\
& 4 & 3.08 & 2.34 & 3.18 & 1.02 & 18.39 \\
& $\mathrm{Avg}$ & 5.79 & 1.98 & 5.78 & 1.10 & 24.82 \\
\hline USD/DEM & 0 & 1.88 & 2.31 & -0.98 & 0.77 & 3.42 \\
& 1 & -0.35 & 2.56 & 0.57 & 1.33 & 0.63 \\
& 2 & -0.96 & 2.76 & 0.86 & 1.38 & 1.05 \\
& 3 & -3.82 & 2.71 & 2.50 & 1.41 & 8.35 \\
& 4 & -5.18 & 2.66 & 3.50 & 1.34 & 18.29 \\
& Avg & -4.25 & 3.60 & 2.82 & 1.93 & 7.70 \\
\hline
\end{tabular}

Panel B: Hypothesis Tests

\begin{tabular}{lcccccccc}
\hline $\begin{array}{l}\text { Exchange } \\
\text { Rate }\end{array}$ & $\mathrm{j}$ & $\beta$ & Std. Err. & $\begin{array}{c}\text { Deg. of } \\
\text { Freedom }\end{array}$ & $\begin{array}{c}\text { LM } \\
\text { Stat. }\end{array}$ & P-value & $\begin{array}{c}\text { Wald } \\
\text { Stat. }\end{array}$ & P-value \\
\hline Both & 0 & $=1$ & & 2 & 7.28 & 0.03 & 8.23 & 0.02 \\
Both & 1 & $=1$ & & 2 & 0.17 & 0.92 & 0.17 & 0.92 \\
Both & 2 & $=1$ & & 2 & 5.59 & 0.06 & 23.66 & 0.00 \\
Both & 3 & $=1$ & & 2 & 1.90 & 0.39 & 2.28 & 0.32 \\
Both & 4 & $=1$ & & 2 & 3.82 & 0.15 & 5.13 & 0.08 \\
\hline Both & 0 & -1.08 & 0.73 & 1 & 0.14 & 0.70 & 0.15 & 0.70 \\
Both & 1 & 0.79 & 1.18 & 1 & 0.13 & 0.71 & 0.14 & 0.71 \\
Both & 2 & 4.07 & 0.78 & 1 & 4.30 & 0.04 & 7.10 & 0.01 \\
Both & 3 & 2.39 & 0.92 & 1 & 0.01 & 0.92 & 0.01 & 0.92 \\
Both & 4 & 3.25 & 0.99 & 1 & 0.08 & 0.78 & 0.08 & 0.77 \\
\hline USD/GBP & 1234 & $=1$ & & 4 & 7.82 & 0.10 & 33.44 & 0.00 \\
USD/DEM & 1234 & $=1$ & & 4 & 5.32 & 0.26 & 6.48 & 0.17 \\
Both & 1234 & $=1$ & & 8 & 11.88 & 0.16 & 59.62 & 0.00 \\
\hline USD/GBP & 1234 & -0.46 & 0.76 & 3 & 8.50 & 0.04 & 15.16 & 0.00 \\
USD/DEM & 1234 & 1.16 & 1.41 & 3 & 5.07 & 0.17 & 5.77 & 0.12 \\
Both & 1234 & 0.47 & 0.65 & 7 & 11.22 & 0.13 & 51.33 & 0.00 \\
\hline
\end{tabular}

Panel A reports coefficient estimates, corresponding standard errors (heteroscedasticity and autocorrelation adjusted) and $\mathrm{R}^{2} \mathrm{~s}$ from the forward premium regression (see Section II.B)

$$
\Delta s_{t, t+1}=\alpha+\beta\left(d i f_{t-j}^{j, j+1}\right)+\varepsilon_{t-j, j+1},
$$

using annual data sampled monthly. All regressions are run using exchange rate data over 1980-2003 (see Section II for a detailed description of the data). Panel B reports tests of the hypotheses that $\beta=1$ and that the $\beta$ s are equal for various combinations of exchange rates and horizons. The Lagrange Multiplier test statistics (LM Stat.) impose the relevant restrictions and the Wald test statistics (Wald Stat.) are based on the unrestricted parameter estimates. We report the restricted parameter estimate and associated standard error where relevant. Rows denoted by "avg" are for regressions where the regressor is the average of the appropriately lagged forward interest rate differentials at horizons $\mathrm{j}=1, \ldots, 4$. 
Table 3: Simulation Results

Panel A: Forward Interest Rate Differential Regressions

\begin{tabular}{|c|c|c|c|c|c|c|c|c|c|c|}
\hline \multirow[b]{2}{*}{ J } & True & & SD & True & Mean & \multirow{2}{*}{\multicolumn{2}{|c|}{$\begin{array}{c}\text { SD } \\
\beta\end{array}$}} & \multirow{2}{*}{$\begin{array}{c}\text { True } \\
\mathrm{R}^{2}\end{array}$} & \multirow{2}{*}{$\begin{array}{c}\text { Mean } \\
\mathrm{R}^{2}\end{array}$} & \multirow{2}{*}{$\begin{array}{l}\text { SD } \\
\mathrm{R}^{2}\end{array}$} \\
\hline & $\alpha$ & $\alpha$ & $\alpha$ & $\beta$ & $\beta$ & & & & & \\
\hline 0 & 0.00 & 0.00 & 0.03 & 1.00 & 1.08 & 0.9 & & 6.38 & 9.72 & 9.92 \\
\hline 1 & 0.00 & 0.00 & 0.03 & 1.00 & 0.97 & 1.1 & & 4.08 & 7.34 & 8.47 \\
\hline 2 & 0.00 & 0.00 & 0.03 & 1.00 & 0.91 & 1.3 & & 2.96 & 6.37 & 7.74 \\
\hline 3 & 0.00 & 0.00 & 0.03 & 1.00 & 0.89 & 1.6 & & 1.87 & 5.59 & 7.06 \\
\hline \multirow[t]{7}{*}{4} & 0.00 & 0.00 & 0.03 & 1.00 & 0.87 & 2.4 & & 0.84 & 4.92 & 6.39 \\
\hline & & \multicolumn{4}{|c|}{ Correlation of $\beta$} & \multicolumn{4}{|c|}{ Correlation of $\mathrm{R}^{2}$} & \\
\hline & & $\mathrm{j}$ & 2 & 3 & 4 & 1 & 2 & 3 & 4 & \\
\hline & & 0.67 & 0.53 & 0.40 & 0.25 & 0.65 & 0.49 & 0.33 & 0.16 & \\
\hline & & 1 & 0.76 & 0.56 & 0.34 & & 0.73 & 0.48 & 0.23 & \\
\hline & & 2 & & 0.72 & 0.43 & & & 0.64 & 0.30 & \\
\hline & & 3 & & & 0.59 & & & & 0.44 & \\
\hline
\end{tabular}

Panel B: Long-Horizon Regressions

\begin{tabular}{|c|c|c|c|c|c|c|c|c|c|c|}
\hline $\mathrm{j}$ & $\begin{array}{c}\text { True } \\
\alpha\end{array}$ & $\begin{array}{c}\text { Mean } \\
\alpha\end{array}$ & $\begin{array}{c}\mathrm{SD} \\
\alpha\end{array}$ & $\begin{array}{c}\text { True } \\
\beta\end{array}$ & $\begin{array}{c}\text { Mean } \\
\beta\end{array}$ & & & $\begin{array}{l}\text { True } \\
\mathrm{R}^{2}\end{array}$ & $\begin{array}{c}\text { Mean } \\
\mathrm{R}^{2}\end{array}$ & $\begin{array}{l}\text { SD } \\
\mathrm{R}^{2}\end{array}$ \\
\hline 0 & 0.00 & 0.00 & 0.03 & 1.00 & 1.08 & & & 6.38 & 9.72 & 9.92 \\
\hline 1 & 0.00 & 0.00 & 0.05 & 1.00 & 1.03 & & & 9.23 & 14.08 & 14.03 \\
\hline 2 & 0.00 & 0.00 & 0.08 & 1.00 & 0.98 & & & 10.79 & 16.69 & 16.39 \\
\hline 3 & 0.00 & 0.00 & 0.10 & 1.00 & 0.93 & & & 11.02 & 17.61 & 17.31 \\
\hline 4 & 0.00 & 0.00 & 0.12 & 1.00 & 0.90 & & & 10.24 & 17.42 & 17.41 \\
\hline & & \multicolumn{4}{|c|}{ Correlation of $\beta$} & \multicolumn{4}{|c|}{ Correlation of $\mathrm{R}^{2}$} & \\
\hline & $\mathrm{j}$ & 1 & 2 & 3 & 4 & 1 & 2 & 3 & 4 & \\
\hline & 0 & 0.84 & 0.73 & 0.63 & 0.53 & 0.82 & 0.70 & 0.58 & 0.45 & \\
\hline & 1 & & 0.93 & 0.83 & 0.71 & & 0.91 & 0.79 & 0.63 & \\
\hline & 2 & & & 0.94 & 0.84 & & & 0.92 & 0.78 & \\
\hline & 3 & & & & 0.94 & & & & 0.92 & \\
\hline
\end{tabular}

Panel C: Hypothesis Tests

\begin{tabular}{rrrrrrrr}
\hline Hypothesis & & \multicolumn{3}{c}{ LM Test } & \multicolumn{3}{c}{ Wald Test } \\
\hline$\beta_{j_{-}=1}$ & Level (\%) & 10.00 & 5.00 & 1.00 & 10.00 & 5.00 & 1.00 \\
& Rejection (\%) & 4.35 & 0.85 & 0.01 & 29.07 & 20.66 & 10.02 \\
$\beta_{j}$ equal & Level (\%) & 10.00 & 5.00 & 1.00 & 10.00 & 5.00 & 1.00 \\
& Rejection (\%) & 4.31 & 0.87 & 0.01 & 19.68 & 12.17 & 4.57 \\
\hline
\end{tabular}

Table 3 reports the results from a Monte Carlo simulation in which we generate 100,000 replications of 24 annual observations from a model that imposes the expectations hypotheses in both interest rates and exchange rates (see Appendix A for a detailed description). Panel A reports statistics on the coefficient estimates and $\mathrm{R}^{2} \mathrm{~s}$ from the forward premium regression (see Section II.B)

$$
\Delta s_{t, t+1}=\alpha+\beta d i f_{t-j}^{j, j+1}+\varepsilon_{t-j, j+1} .
$$

Panel B reports the same statistics for the long-horizon regression, after Chinn and Meredith (2005),

$$
\Delta s_{t, t+1+j}=\alpha+\beta d i_{t, j}+\varepsilon_{t, j} .
$$

"True" refers to the analytical (infinite sample) value, and "Mean" and "SD" refer to the mean and standard deviation of the values across the simulations. For the test statistics, Panel C reports the percent of the simulations that reject the null hypothesis at the $10 \%, 5 \%$, and $1 \%$ levels. 
Table 4: The Expectations Hypothesis of Interest Rates

\begin{tabular}{llccccr}
\hline Country & $\mathrm{j}$ & $\alpha$ & Std. err. & $\beta$ & Std. err. & $\mathrm{R}^{2}$ \\
\hline US & 1 & -0.37 & 0.33 & 0.00 & 0.25 & 0.00 \\
& 2 & -0.72 & 0.81 & 0.13 & 0.45 & 0.30 \\
& 3 & -1.39 & 1.12 & 0.70 & 0.38 & 7.04 \\
& 4 & -2.06 & 1.12 & 1.16 & 0.24 & 19.15 \\
\hline UK & 1 & -0.24 & 0.29 & 0.47 & 0.22 & 8.84 \\
& 2 & -0.78 & 0.56 & 1.00 & 0.27 & 25.78 \\
& 3 & -1.03 & 0.71 & 1.18 & 0.31 & 33.92 \\
& 4 & -1.47 & 0.71 & 1.40 & 0.33 & 46.18 \\
\hline \multirow{2}{*}{ Germany } & 1 & -0.36 & 0.34 & 0.48 & 0.19 & 6.28 \\
& 2 & -0.96 & 0.54 & 1.01 & 0.28 & 20.04 \\
& 3 & -1.66 & 0.54 & 1.40 & 0.35 & 36.28 \\
& 4 & -2.33 & 0.50 & 1.62 & 0.30 & 50.47 \\
\hline
\end{tabular}

Table 4 reports coefficient estimates, corresponding standard errors (heteroscedasticity and autocorrelation adjusted) and $\mathrm{R}^{2} \mathrm{~s}$ from the estimation of the expectations hypothesis of interest rates country-by-country (see Section IV.A):

$$
i_{t+j, 1}-i_{t, 1}=\alpha+\beta\left(i f_{t}^{j, j+1}-i_{t, 1}\right)+\varepsilon_{t, j},
$$

using annual data sampled monthly. The regressions are run using interest rate date over 1980-2003, 1979$2002,1978-2001$, and $1977-2000$ for horizons $j=1, \ldots, 4$, respectively, for a total of 288 monthly observations in all cases. See Section II for a detailed description of the data. 
Table 5: The Expectations Hypothesis of Interest Rates and Exchange Rates

\begin{tabular}{lcccccccr}
\hline $\begin{array}{l}\text { Exchange } \\
\text { Rate }\end{array}$ & $\mathrm{j}$ & $\alpha$ & Std. err. & $\beta$ & Std. err. & $\gamma$ & Std. err. & $\mathrm{R}^{2}$ \\
\hline USD/GBP & 1 & -2.01 & 2.52 & 0.23 & 1.51 & -1.63 & 0.84 & 9.92 \\
& 2 & 1.84 & 2.26 & 2.99 & 1.22 & -1.24 & 0.70 & 32.50 \\
& 3 & -0.59 & 2.46 & 1.01 & 1.58 & -1.05 & 0.95 & 12.27 \\
& 4 & 1.71 & 2.58 & 2.35 & 1.51 & -0.56 & 0.88 & 19.33 \\
& $\mathrm{Avg}$ & 3.63 & 2.47 & 4.52 & 1.58 & -1.01 & 0.80 & 28.30 \\
\hline USD/DEM & 1 & -1.23 & 2.59 & 0.53 & 1.31 & -2.79 & 0.99 & 13.50 \\
& 2 & -0.62 & 2.71 & 0.31 & 1.46 & -1.38 & 0.72 & 6.88 \\
& 3 & -2.77 & 2.73 & 1.58 & 1.61 & -1.28 & 0.80 & 14.04 \\
& 4 & -3.87 & 2.84 & 2.49 & 1.63 & -1.11 & 0.91 & 22.69 \\
& $\mathrm{Avg}$ & -4.56 & 3.28 & 2.54 & 1.82 & -2.03 & 0.83 & 19.58 \\
\hline
\end{tabular}

Table 5 reports coefficient estimates, corresponding standard errors (heteroscedasticity and autocorrelation adjusted) and $\mathrm{R}^{2} \mathrm{~s}$ from the estimation of the augmented forward premium regression (see Section IV.B for details):

$$
\Delta s_{t, t+1}=\alpha+\beta d i f_{t-j}^{j, j+1}+\gamma u_{t-j, j}^{1}+\varepsilon_{t-j, j+1} .
$$

using annual data sampled monthly. All regressions are run using exchange rate data over 1980-2003 (see Section II for a detailed description of the data). "Avg" denotes that the regressor is the average of the appropriately lagged forward interest rate differentials at horizons $j=1, \ldots, 4$. 


\section{Table 6: Inflation}

\begin{tabular}{lcccccr}
\hline Country & $\mathrm{j}$ & $\alpha$ & Std. err. & $\beta$ & Std. err. & $\mathrm{R}^{2}$ \\
\hline US & 1 & -0.84 & 0.31 & 0.79 & 0.27 & 17.08 \\
& 2 & -1.71 & 0.45 & 1.16 & 0.28 & 35.72 \\
& 3 & -2.31 & 0.61 & 1.30 & 0.36 & 37.25 \\
& 4 & -2.66 & 0.64 & 1.25 & 0.33 & 34.89 \\
\hline UK & 1 & -0.54 & 0.38 & 0.18 & 0.29 & 0.91 \\
& 2 & -1.11 & 0.62 & 0.49 & 0.30 & 4.97 \\
& 3 & -1.42 & 0.75 & 0.59 & 0.29 & 6.24 \\
& 4 & -1.87 & 0.77 & 0.20 & 0.30 & 0.76 \\
\hline \multirow{2}{*}{ Germany } & 1 & -0.31 & 0.21 & 0.40 & 0.22 & 7.40 \\
& 2 & -0.74 & 0.32 & 0.60 & 0.23 & 15.40 \\
& 3 & -1.22 & 0.34 & 0.86 & 0.20 & 29.66 \\
& 4 & -1.78 & 0.36 & 1.07 & 0.19 & 46.34 \\
\hline
\end{tabular}

Table 6 reports coefficient estimates, corresponding standard errors (heteroscedasticity and autocorrelation adjusted) and $\mathrm{R}^{2} \mathrm{~s}$ from the estimation of the inflation regression country-by-country (see Section IV.C for details):

$$
\pi_{t+j, 1}-\pi_{t, 1}=\alpha+\beta\left(i f_{t}^{j, j+1}-i_{t, 1}\right)+\varepsilon_{t, j},
$$

using annual data sampled monthly. All regressions are run using inflation data over 1980-2003 (see Section II for a detailed description of the data). 
Table 7: The Information in the

Average Contemporaneous Forward Interest Rate Differential

\begin{tabular}{lccccccc}
\hline $\begin{array}{l}\text { Exchange } \\
\text { rate }\end{array}$ & $\alpha$ & Std. err. & $\beta$ & Std. err. & $\gamma$ & Std. err. & $\mathrm{R}^{2}$ \\
\hline USD/GBP & -3.34 & 2.12 & -1.09 & 1.45 & -1.43 & 1.29 & 5.90 \\
USD/DEM & 0.68 & 2.57 & -0.36 & 1.51 & -1.66 & 1.32 & 4.28 \\
\hline
\end{tabular}

Table 7 reports coefficient estimates, corresponding standard errors (heteroscedasticity and autocorrelation adjusted) and $\mathrm{R}^{2} \mathrm{~s}$ from the estimation of the exchange rate regression with contemporaneous forward rate differentials (see Section V.A for details):

$$
\Delta s_{t, t+1}=\alpha+\beta\left[\frac{1}{4} \sum_{j=1}^{4} d i f_{t}^{j, j+1}\right]+\gamma u_{t, a v g}+\varepsilon_{t, 1},
$$

using annual data sampled monthly. All regressions are run using exchange rate data over 1980-2003 (see Section II for a detailed description of the data). 
Table 8: Out-of-Sample Forecasting

\begin{tabular}{|c|c|c|c|c|c|c|c|c|c|}
\hline \multirow{2}{*}{$\begin{array}{r}\text { Exchange } \\
\text { rate }\end{array}$} & & \multirow{2}{*}{$\begin{array}{r}\text { Random } \\
\text { walk }\end{array}$} & \multirow[b]{2}{*}{$d i_{t, 1}$} & \multicolumn{4}{|c|}{$d i f_{t-j}^{j, j+1}$} & \multirow{2}{*}{$\frac{1}{4} \sum_{j=1}^{4} d i f_{t-j}^{j, j+1}$} & \multirow{2}{*}{$\frac{1}{4} \sum_{j=1}^{4} d i f_{t}^{j, j+1}$} \\
\hline & & & & $j=1$ & $j=2$ & $j=3$ & $j=4$ & & \\
\hline \multirow[t]{5}{*}{ USD/GBP } & RMSE & 11.37 & 12.05 & 11.25 & 10.68 & 11.00 & 10.77 & 10.88 & 11.56 \\
\hline & In-sample $\mathrm{R}^{2}$ & 0.00 & 5.85 & 1.49 & 27.20 & 8.54 & 18.39 & 24.82 & 5.90 \\
\hline & OOS $R^{2}$ & 0.00 & -12.24 & 2.20 & 11.87 & 6.41 & 10.35 & 8.50 & -3.38 \\
\hline & Test & NA & -1.32 & 0.43 & 1.82 & 0.99 & 1.32 & 1.45 & -0.82 \\
\hline & P-value & NA & 0.91 & 0.33 & 0.03 & 0.16 & 0.09 & 0.07 & 0.79 \\
\hline \multirow[t]{5}{*}{ USD/DEM } & RMSE & 13.41 & 14.10 & 13.42 & 13.38 & 13.08 & 12.82 & 13.14 & 13.69 \\
\hline & In-sample $\mathrm{R}^{2}$ & 0.00 & 3.42 & 0.63 & 1.05 & 8.35 & 18.29 & 7.70 & 4.28 \\
\hline & OOS R ${ }^{2}$ & 0.00 & -10.68 & -0.18 & 0.42 & 4.76 & 8.51 & 3.97 & -4.22 \\
\hline & Test & NA & -1.28 & -0.02 & 0.05 & 0.55 & 0.99 & 0.45 & -0.48 \\
\hline & P-value & NA & 0.90 & 0.51 & 0.48 & 0.29 & 0.16 & 0.33 & 0.68 \\
\hline
\end{tabular}

Table 8 reports results from an out-of-sample exchange rate forecasting exercise using five models: (1) the random walk, (2) interest rate differentials, (3) lagged forward interest rate differentials (for horizons $j=1, \ldots, 4),(4)$ the average lagged forward interest rate differential, and (5) the average contemporaneous forward interest rate differential. For the latter four models, a coefficient of 1 is imposed on the predictor variable, consistent with the relevant theory (see Section V.B for details). The table reports the root mean squared forecast error (RMSE), the in-sample $\mathrm{R}^{2}$, and the out-of-sample (OOS) $\mathrm{R}^{2}$. In addition, we report the test statistic and p-value for a test of the null hypothesis that the particular model has forecasting power equal to that of the random walk model against the alternative that the particular model is superior (see Appendix B for details). The sample period is the full 1980-2003 sample (288 observations) in each case. 